\title{
The Accentual Pattern and Prosody of the Chonnam Dialect of Korean
}

\author{
Sun-Ah Jun
}

Ohio State University

\begin{abstract}
This paper examines the pitch accent properties of the South Cholla (Chonnam) dialect. The Chonnam dialect has two kinds of accentual patterns, Low-High-Low and High-High-Low, which are determined by the properties of the first segment of a phrase. The domain of the accentual pattem is a Phonological phrase in the prosodic hierarchy postulated in Selkirk (1980, 1984) and Nespor and Vogel (1982, 1986), assuming a phonological word is the same as a morphological word, a lexical word plus any postnominal particles and inflectional endings. Basically each phonological word can form one accentual phrase. However, more than one phonological word can form one accentual phrase due to semantic factors or focus variation. It is also argued that the Chonnam dialect has two more units of prosodic structure above the phonological phrase within an utterance, namely the Intermediate Phrase and the Intonational Phrase (Beckman and Pierrehumbert 1986). An Intermediate phrase in Chonnam is characterized as the domain of downstep between phonological phrases. An Intonational phrase is characterized by a High or High-Low boundary tone. The data used in this paper are from the dialect spoken in Kwangju, the main city in the Chonnam province.
\end{abstract}

\section{Introduction}

The Korean language can be divided into eight dialects, roughly corresponding to provincial areas: Hamkyung, Pyungan, Hwanghay, Central dialect (Kyungki, Kangwon), Chungchung, Kyungsang, Cholla, and Cheju. Among these, it has been claimed (e.g. Ramsey 1978) that the richest accentual systems are found in the dialects of Hamkyung and Kyungsang. It is also believed that the lexical pitch accent systems of these modern dialects of Korea are the remnants of the Middle Korean tone system. (Middle Korean was the language of 15th and 16th century Korea and apparently had lexical tone properties similar to those of Chinese.)

The pitch accent properties of the South Cholla (henceforth Chonnam) dialect are poorly studied. Yi (1983) only mentions that North Kyungsang and Chonnam

'To appear in Y. Yang, S. Kuno, I. H. Lee and J. Whitman, eds., Harvard Studies in Korean Linguistics III (1990). 
dialects have pitch accents and still retain a vowel length contrast. ${ }^{2}$ In addition to having a different pattern of intonation from that of the standard (Seoul) dialect, the Chonnam dialect differs from other dialects in that it has a property of phrasal pitch accent.

In this paper, I argue that the pitch accent of Chonnam dialect is not the property of lexical items, but of phrases, and that the phrasal domain of the pitch accent is the Phonological Phrase (P-Phrase) in the Prosodic Hierarchy postulated in Selkirk $(1980,1984)$ and Nespor and Vogel $(1982,1986)$, etc. Furthermore I argue that the Chonnam dialect has three more units of prosodic structure above the Phonological phrase - namely the Intermediate phrase, the Intonational phrase and the Utterance, based on such features as the domain of downstep. Finally I show that these prosodic structures are not isomorphic to syntactic constituents.

The data used in this paper are from the dialect spoken in Kwangju, the main city in the Chonnam province. The primary informant was the author, who lived in Kwangju until her mid-twenties. Corroborating judgements and utterances were obtained from other Chonnam native speakers, I. Park and Y. Yoon. Throughout this paper, $E$ refers to a schwa sound, $N$ refers to a velar sound, $x^{h}$ an aspirated sound and $x^{\prime}$ a tense or glottalized sound. Also, a lenis stop is voiced between [+sonorant] segments within the domain of the pitch accent. But for easy recognition of a lexical item, the underlying form is used. Curly braces, ( ), are used for representing an accentual phrase.

\section{The Chonnam Accentual Pattern}

In the Chonnam dialect there are two kinds of pitch accent patterns: one is Low-High-Low (LHL) and the other is High-High-Low (HHL). Each tone is associated with one mora from left to right within a domain, which I will call the accentual phrase, and which is the topic of the next section. Any leftover tone is associated with the final mora and any leftover mora is associated with the final tone. Since an accentual phrase is often exactly one phonological word, one might assume that a word has its own lexical tonal property. The following are representative examples illustrating accentual patterns of phrases which consist of a single lexical item only:

${ }^{2}$ Yi (1983) claims that a long vowel had a rising tone in Middle Korean and that even though the tone of a word disappeared around the end of the 16th century, two-dot words appear to have retained length even to the present time, especially in the first syllable. So he claims that vowel length contrasts in modern dialects of Korean indicate that Korean was a tone language. 
(1)

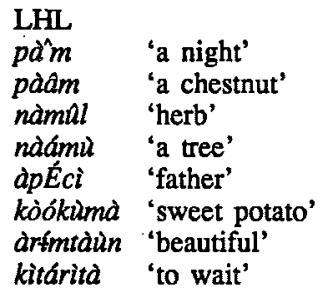

\begin{tabular}{|c|c|}
\hline 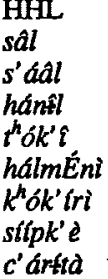 & $\begin{array}{l}\text { 'flesh' ' } \\
\text { 'rice' } \\
\text { 'a sky' } \\
\text { 'a rabbit' } \\
\text { 'grandma' } \\
\text { 'an elephant' } \\
\text { 'easily' } \\
\text { 'to cut' }\end{array}$ \\
\hline
\end{tabular}

(Acute accent marks $\mathrm{H}$ tone and grave accent $\mathrm{L}$ tone. In monosyllabic words with short vowels, the HHL pattern is phonetically realized as $\mathrm{HL}$ by the twin sister convention.)

A Phonological word in Chonnam consists of a lexical item (Noun, Verb, Adjective, Adverb, or Determiner, etc.) and any postnominal particles or inflectional endings, since palatalization of dental stops, which applies only lexically, also applies between a lexical item and particles as in tot 'to rise' $+i$ 'nominalizer' $=\Rightarrow$ toci 'rising' and a $^{h}$ 'a field' $+i$ 'Subj.' $\Rightarrow$ pac $^{h} i$ 'a field - subject' (Cho 1987). Thus, when a noun is followed by more than one postnominal particle, they always form one accentual phrase as a single phonological word. For example, sasim 'a

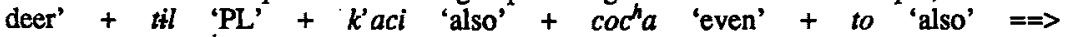
\{sásimtilk'acicochato\} $^{3}$ 'even deer, too,...' or pat 'to receive' + ass 'PAST' + ta 'verbal ending' $=>$ (patátt'a\} 'received'. However the fact that a phonological word often forms a domain of accentual phrase does not mean that the pattern of accentual phrase is a property of a lexical item. Four facts show that the tonal or accentual property is determined postlexically.

\subsection{Arguments for the Post-lexical Status of the Accent Pattern}

First, the accentual pattern of each lexical item is predictable and exceptionless. That is, the tonal property is not lexeme-specific. Whether a lexical item has the LHL pattern or the HHL pattern depends only on its first segment without exceptions. When the first segment has a laryngeal feature of either [+spread] or [+constricted] such as $/ p^{h}, t^{h}, k^{h}, c^{h}, h, s, p^{\prime}, t^{\prime}, k^{\prime}, c^{\prime}, s^{\prime} /$, the phrase shows the HHI accentual pattern and any phrase whose first segment does not have these laryngeal properties shows the LHL pattern. The following sets of related onomatopoeic words confirm the fact that only the phrase initial segment is relevant to the type of each accentual pattern.

a. LHL: tallaNtallaN 'tinkling jingling'

HHL: t'alláN'allaN 'louder noise than usual tinkling jingling'

HHL: $t^{h}$ allaNt allaN 'lighter noise than usual or sounds empty'

${ }^{3}$ Henceforth, any vowel lacking a tone mark is assumed to have a $\mathrm{L}$. 
b. LHL: panc'ákpanc'ak 'twinkle twinkle'

HHL: $p^{\prime} a ́ n c$ 'ákp'anc'ak 'much more twinkling than usual'

c. LHL: cóblcol 'trickling or bubbling noise or its appearance'

HHL: c'ólc'ol 'weakened noise of bubbling due to small amount of water'

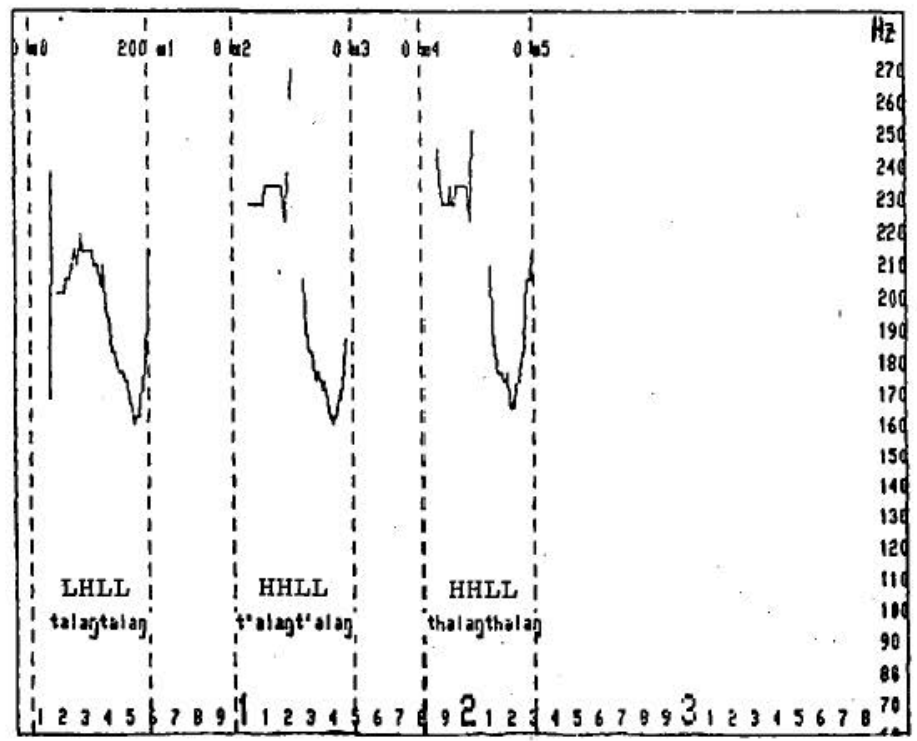

Figure 1: FO tracks of utterances in (2a).

Figure 1 shows the fundamental frequency (henceforth F0) tracks for the three words in (2a) above, illustrating the contrast between LHL and HHL. Since the two kinds of accentual patterns differ only in their first tone, $\mathrm{L}$ or $\mathrm{H}$, and the tones are predictable from the phrase-initial segment, we can characterize the Chonnam accentual pattern as not lexeme-specific; it could be determined postlexically, as a phrasal accent.

The second argument for characterizing these patterns as a phrasal accent involves the interaction between the domain of phrasal accent and that of vowel shortening and that of resyllabification. In some dialects of Korean which still preserves the Middle Korean vowel-length contrast, a long vowel occurs only in 
word-initial position. The Chonnam dialect has a vowel shortening rule which applies both lexically and postlexically.

The rule is that a long vowel in a word-initial syllable becomes short when the word occurs non-initially in a compound such as saaram 'a man' of nuuns'aram 'a snowman' or suukEn 'a towel' of sons' $\underline{k} k E n$ 'a handkerchief'. ${ }^{4}$ This is the lexical application of the rule. The vowel also becomes short when the word occurs in certain non-phrase-initial positions such as $r$ 'this' + sáárdm 'a man' $\Rightarrow$ ' $i$ síram\} 'this man' or nóórdn 'yellow' + suukEn 'a towel' $\Longrightarrow$ [nóóran sükEn\} 'a yellow towel'. This is the postlexical version of the rule. Note, however, that if these phrases form two accentual phrases with each word constituting one accentual phrase, then each second word is pronounced with the first syllable long, as in $\{\hat{i}\}$ (sáardm) and (ndoooràn\} (súúkÉn). A formalization of the vowel shortening rule looks like the following.

$$
\begin{aligned}
& \mathrm{V}:->\mathrm{V} /\left(\mathrm{C}_{\mathrm{o}}^{2} \mathrm{VX}\right. \\
& \text { (here, } \mathrm{X} \text { is any string, and } \mathrm{I} \text { is a domain boundary.) }
\end{aligned}
$$

In addition to the vowel shortening rule, the domain of postlexical resyllabification is also the same as that of an accentual pattern, since the vowel shortening rule is accompanied by a resyllabification of the coda of the preceding syllable if the shortened vowel is originally syllable initial. For example, $E E p$ 'not

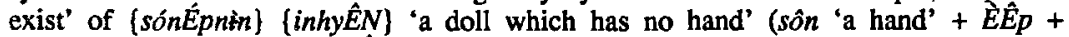
nin 'relative marker' + inhy $\hat{E} N$ 'a doll') is shortened since it is not a domain-initial syllable. It is also resyllabified by getting an onset from the coda of the preceding morpherne, here $n$, when the P-word EEpnin does not form its own accentual phrase. But when EEpnin forms an accentual phrase by itself the resyllabification does not apply between son and EEpnin and EEpnin is not shortened since it does not satisfy the structural description of rule (3) above. Thus, since the domain of the postlexical vowel shortening rule and resyllabification rules lines up with the domain of the accentual pattern, and an accentual phrase can contain more than one phonological word, our pitch accent must be a phrasal accent. The following examples clearly illustrate that the Chonnam accentual pattern is not a property of a phonological word.

${ }^{4}$ Only a few verbal adjectives preserve their vowel length even before a syllable beginning with a vowel of a different morpheme. For example,

i. $\quad \operatorname{cooh}$ 'to be good' + ta 'verbal ending' $\Rightarrow\{$ coóth $a\}$ $c o o h+a s^{\prime}$ 'PAST' $+t a \Rightarrow$ coóas't'a $\left({ }^{*} \operatorname{cod} s^{\prime} t\right.$ ' $\left.\left.a\right)\right\}$

ii. [cEÉkt'a] 'to be small (amount)' - $\left\{c E E E k E s^{\prime} t^{\prime} a\right\}$ ' was small'

iii. (mainth $a\}$ 'to be a lot (amount)' - (maáas't'a\} 'was a lot'

iv. $\{$ cadkt'a\} 'to be small (height)' - \{cadas't'a\} 'was small' 
(4) $k^{h} \hat{t}+n$ 'big' + kifrim 'a picture'- kwa 'and' + cabkin 'small' + kifrim 'a picture' $\Rightarrow\left\{k^{h}\right.$ fnkfrimkwd $\}$ \{cdákinktrim $\}$ 'a big picture and a small picture'

In (4), since 'big' and 'small' are contrasted, each is focused by being the head of an accentual phrase containing the following noun. kitrim has a long first syllable by itself and since its first segment has neither of the relevant laryngeal features mentioned above, it gets the LHL accentual pattern if it forms its own accentual phrase. But the long vowel becomes short when the word occurs in non-initial position, as in $k^{h}$ inkirimkwa 'big picture and...'; regardless of the original LH tone, the shortened vowel gets a $\mathrm{H}$ tone since the shortened vowel is the second mora of the whole phrase. Here, the first segment of the whole phrase, $k^{k}$, has the [+spread] feature, and thus the whole phrase gets HHL pattern. If the LH of $k+$ were a lexical tone, then the shortened vowel would get a contour tone like $k^{h}+$ fnktrim, or $^{2}$ would get a contour tone like $k^{h} \hat{\imath} n k$ trîm but it does not. This is true for all the cases of other long vowels shortened due to the position of a word within a single accentual phrase. Thus the non-initial lexical item within a phrase does not affect the accentual pattern of the whole phrase and the accentual pattern of the phrase is associated with each mora of the whole phrase postlexically.

The third argument for the accent pattern being post-lexical is seen in the comparison of the domain of the Korean Lenis Stop Voicing rule with that of the accentual pattern. A lenis stop is voiced between voiced sounds as in (5).

\section{(5) Lenis Stop Voicing Rule}

$$
\left[\begin{array}{l}
\text {-cont, }- \text { asp } \\
\text {-tense }
\end{array}\right] \quad \rightarrow[+ \text { voice }] /[+ \text { voice }] \_[+ \text {voice }]
$$

Cho (1987) argues that this voicing rule applies both lexically and postlexically. So, in addition to the fact that $a p E c i$ becomes $a b E j i, k \dot{t}$ 'that' $+c i p$ 'a house' becomes $k$ ijip and $k^{h}$ in 'big' $+k$ kitim 'a picture' becomes $k^{h}{ }_{i n g}$ irim by the Lenis Stop Voicing rule. Cho (1987) claims that in the Seoul dialect the domain of this rule is P-Phrase (with some stipulation over Selkirk's end-based theory). In the Chonnam dialect, the domain may correspond to the domain of accentual phrase because in Chonnam cip 'a house' or kitrim 'a picture' is not voiced when it forms an accentual phrase of its own. Also the $p$ of pap 'rice' in kigamEkninbap 'the rice he eats' ( $k \dot{f}$ 'he' + $k a$ 'Subj.' + $m E k$ 'to eat' $+n i n$ 'Rel. marker' + pap 'rice') is voiced when the whole phrase forms one accentual phrase but is not voiced when it forms its own accentual phrase, as in (kigdmENnin\} \{pdip\}. Therefore, since the domain of the postlexical Lenis Stop Voicing rule also lines up with that of the accentual pattern, the domain of the accentual pattern should be larger than a phonological word, and the accentual pattern should be determined post-lexically.

The fourth argument for characterizing these patterns as a phrasal accent involves words which have an alternate contracted form. When the contracted word forms one accentual phrase together with a following or preceding word, the tone of 
the deleted or contracted syllable ignores the original morpheme boundary and only refers to the number of the syllables in the whole phrase in which it occurs. Consider the following examples.

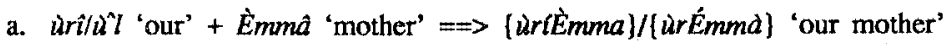

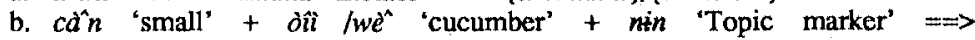
[canóinin]/(canwénìn\} 'a small cucumber is ...' or 'as for a small cucumber'

Here, oi has a contracted form as we, one syllable with a short vowel, and uri becomes $u l$, one syllable with short vowel. ${ }^{s}$ However, when they form one accentual phrase together with the following or preceding noun (as indicated by the resyllabification of $u l$ as $u r$ ), the tone of the deleted vowel does not care about its original morpheme boundary. Instead each mora gets a tone automatically according to the position within the newly formed accentual phrase. In other words, the tonal pattern, LHL or HHL, determined by the laryngeal feature of the first segment of the whole phrase, matches to morae from left to right within an accentual phrase.

So far we have seen that the Chonnam pitch accent is a phrasal accent. The pitch accent assignment rule, therefore, should be postlexical and the domain of this rule should be larger than the phonological word. It can be identified with the P-Phrase in the prosodic hierarchy suggested by Nespor and Vogel $(1982,1986)$ and Selkirk $(1980,1986)$, and others.

\subsection{The Underlying Form and Derivational Rules}

Since there are two accentual patterns in Chonnam, we might assume both of the accentual patterns as basic and assign each accentual pattem directly to phrases depending on their first segments. On the other hand, we may also assume one of the accentual pattern as basic and derive the other pattern by phonological rules. Under the second assumption, I argue that the LHL pattern is underlying and HHL is derived from that, since it is known cross-linguistically that aspirated or glottalized segments cause higher F0 at the onset of the following vowel (Hombert 1978). Moreover, Hardcastle (1973), Kim (1965, 1970), Kagaya (1974) and others all show that the $\mathrm{FO}$ at the onset of a vowel following a Korean aspirated or fortis (or glottalized) initial stop is higher than that following a lenis (or voiceless unaspirated) initial stop, although there is some overlapping in the Fo values for some subjects.

${ }^{5}$ uri usually becomes $u l$ before certain nouns referring to a close family relation and beginning with a vowel such as Emma 'mom', EmmEni 'mother', $a p^{\prime} a$ 'dad', apEci 'father', Enni 'elder sister', op'a 'elder brother', and eeki 'baby', but not before imo 'aunt' or acEs' $i$ 'uncle' or 'a man of one's parents' age'. 
These phonetic explanations, however, do not mean that the HHL pattern is a low-level product of the physiological effect. Rather, the physiological effect only provides a good motivation for assuming the LHL pattern as the underlying one. This is clear if we compare the F0 contours of the CV series in a non-accentual dialect of Korean like Seoul dialect with those of Chonnam. The Chonnam HHL accentual pattern is different from the pattern of phonetically raised F0 mentioned above in that the beginning of the Chonnam HHL pattern shows a steady state of high frequency until it reaches the second mora as shown in Figure 2, while the portion of the vowel with naturally raised F0 after aspirated or glottalized stops in the Seoul dialect is much shorter according to the reports of it in the literature (e.g. Han and Weitzman 1970).

Figure 2 shows the F0 tracks of nonsense words of stop and vowel uttered by a Chonnam native speaker.

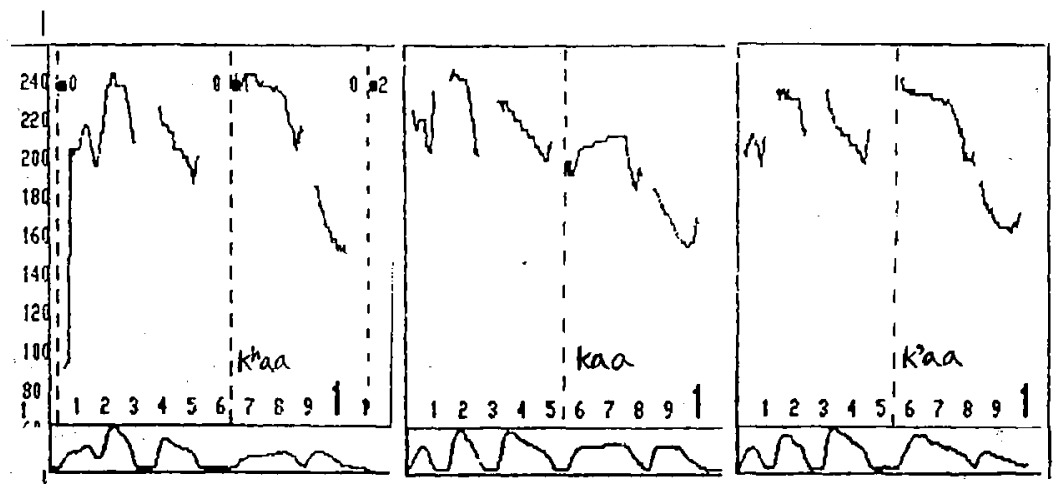

Figure 2: The nonsense words $k^{h} a a-k a a-k^{\prime} a a$ uttered by a Chonnam speaker in the carrier sentence ' $I k E$ sin $t a$ ' 'this is

Accordingly, assuming the LHL accentual pattern is underlying, three phonological rules would be needed to derive the HHL pattern. First, within the domain of accentual phrase one-to-one left-to-right mapping would apply between tones and morae (Tone-Mora Mapping). Next, if the first segment has the relevant laryngeal features, delete the first $L$ and finally, spread $H$ to its left mora (L-delinking and H-spreading) shown in (7).

Since L-delinking and H-spreading only occur at the beginning of a P-Phrase we need a left end of P-Phrase mark for them. Conversely, since the $L$ tone 
spreads only to the end of P-Phrase we need a right end of P-Phrase mark for the L-spreading rule.

(7) a. L-delinking \& H-spreading

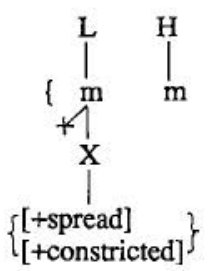

(where ( is a mark for the beginning of the domain and ' $\mathrm{m}$ ' for mora $\mathbf{X}$ for CV-skeleton and +4 is Pulleyblank (1986)'s notation for something with no association to the left.)

Among segments containing the relevant laryngeal features, only the status of $s$ is a problem, because Korean $s$ has usually been assumed to belong with the lenis stop phonemes, $/ p, t, k /$, for various reasons, one of which is that it is subject to the Korean Tensing rule after a nasal or obstruent coda as are the lenis stops (Obstruent Tensing rule).
a. nun 'an eye' + tooNca 'a ball' $\Longrightarrow$ nunt' $O N c a$ 'an eyeball'
b. nun 'an eye' + pyEEN 'disease' $\Rightarrow$ nunp' $y E N$ 'an eye disease'
c. nun 'an eye' + cimcak 'a guess' $\Rightarrow$ nunc'imcak 'eye measurement'
d. nuun 'snow' + kil 'a road' $\Rightarrow$ nuunk'il 'a snow road'
e. nuun 'snow' + saaram 'a man' $=\Rightarrow$ nuuns' aram 'a snowman'
f. $\operatorname{cip}$ 'a house' $+c a N s a$ 'a dealing' $\Rightarrow$ cipc'aNsa 'a house dealing business'
g. cip 'a house' + saaram 'a man' $\Rightarrow$ cips'aram 'a housewife'

However, Kagaya (1974) claims that Korean $s$ belongs with the aspirated consonants in that it causes a higher F0 on the following vowel just as $p^{h}, t^{h}, k^{h}$ do and also in that its glottal width over time in a CV sequence is similar to that of the aspirated stops. Figure 3 shows the glottal width over time for representative utterance samples of each type of consonant in a CV sequence (Kagaya 1974: 164). Since any phrase beginning with $s$ starts with a High tone in Chonnam dialect, this supports the argument for Korean $s$ belonging with the aspirated consonant phonemes rather than with the lenis phonemes.

\section{Domains of the Accentual Pattern and the Prosodic Structure of Chonnam}

So far we have seen that the Chonnam accentual pattern is a property of a phonological phrase at some level. Our next question is what determines the 

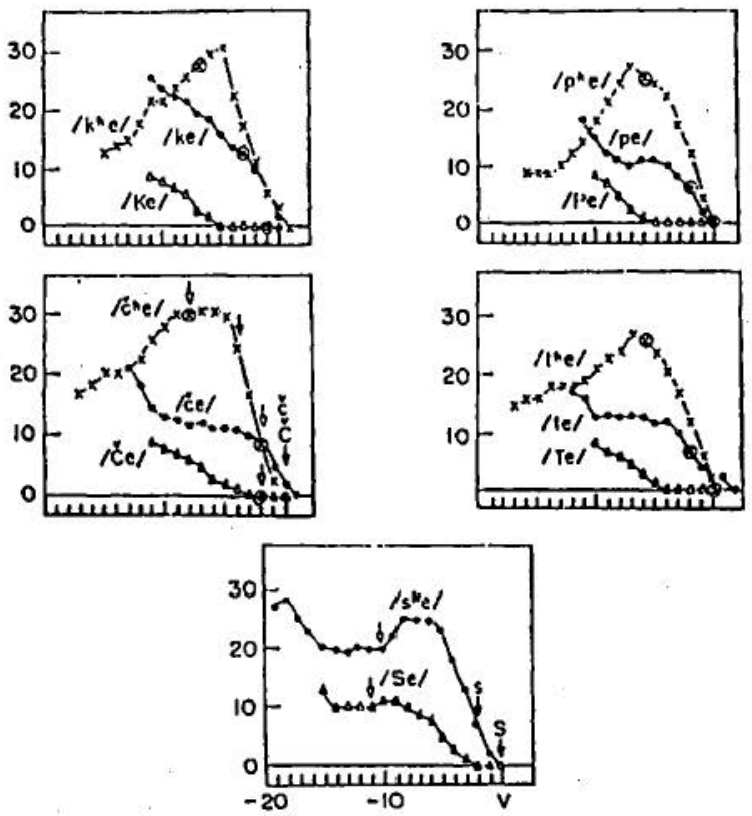

Figure 3: The ordinate gives the apparent glottal width in an arbitrary scale. A small circle marks articulatory explosion. An empty head arrow marks frication onset; a filled head arrow marks frication offset.

phonological phrasing at this level. Although the domain of the accentual pattern roughly matches syntactic constituents, in a conversation the phrasing is influenced by factors other than syntactic constituents, such as semantic factors, length of domain, emphasis on some specific morphemes, or morpheme inherent properties. However, based on the degree of generality across possible accentual domains, we can find several criteria by which we can predict a possible accentual phrasing.

\subsection{Domains of the Accentual Pattern}

Basically, each phonological word (henceforth P-Word) can potentially form one accentual domain (henceforth P-Phrase). But a P-word does not always form 
its own P-Phrase. Rather it can form one P-Phrase together with the preceding or following P-Word. When the P-word is a noun and it is 'old information' expectable from the context, or it is a function word such as te 'a place', $p a$ 'a fact', $k E t$ 'a thing', etc., (which are usually bound-morpheme-like pronouns), or it functions as a kind of semantic proto-type, the P-Word, a noun, does not form its own P-Phrase but is included in a larger P-Phrase together with the preceding P-Word. So, for example, when the word saaram is used specifically to mean 'a man' in opposition to 'an animal', saaram forms its own P-Phrase, but when it is used meaning 'someone' as a pro-word, it does not form its own P-Phrase but belongs to the P-Phrase of the preceding modifier. Some examples are as follows:
a. $k^{h}$ in 'big' + caaNkap 'a glove' $\Rightarrow\left\{k^{h} \hat{t}\right\}$ \{caáNkap\} 'a big glove'

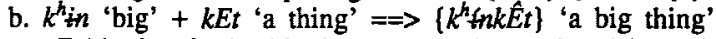
c. $c E$ 'that' + ke 'a thing' + saaram 'a man' $+i$ 'to be' + nya
'question particle' $=>\{c E k \hat{e}\}$ (sááraminya)? 'Is that a man?'
d. $p y E E N w E n$ 'a hospital' $+e$ 'in' + iss 'to exist or to stay' + nin 'relative particle' $+a p^{\text {inn }}$ 'sick' + saaram 'a man' $\Rightarrow$ (pyEÉNwEne innin $)$ [aphtnsaram\} 'someone who is sick in the hospital'

(9a) above is a normal case of two accentual phrases for \{Adj\} \{Noun\}, but in (9b) the adjective and noun form one P-Phrase $\{$ Adj+Noun\} since the noun is a bound-morpheme-like pronoun. In (9d), saaram does not have any specifio meaning but is a semantically proto-type noun, while saaram of $(9 \mathrm{c})$ has a literal meaning of 'something which is a man'. So the saaram in (9c) forms a separate P-Phrase of its own while that in (9d) does not.

Next, when a P-Word is intentionally or contextually focused or emphasized, it always forms one P-Phrase absorbing, regardless of any syntactic boundary, all the following P-Words within the Intonational Phrase, which otherwise would have their own P-Phrases. For example, consider (10) and (11).

(10) acu 'very' + nooran 'yellow' + suukEn 'a towel' $\Rightarrow$

a. $\{a c a\}$ \{noóran\} (súúkEn\} 'a very yellow towel'

b. (acú noran sukEn\} 'a VERY yellow towel'

c. $\{a c a\}$ (noóran sukEn] 'a very YELLOW towel (not a green towel)'

d. $\{a c a\}$ [noóran\} \{súúkEn\} 'a very yellow TOWEL (not a yellow book)'

(11) Emma 'mom' + $k a$ 'subject marker' + mantil 'to make' $+n$ 'relative marker' + mantukuk 'a wonton soup' $+m E k$ 'to eat' + . Ess 'PAST' $+E$ 'verbal ending' $=\Rightarrow$ 
a. $\left\{\right.$ Emmáka\} $\left\{\right.$ mantìn\} (mantükuk mEkEs'E\} ${ }^{6}$ '(I) ate a wonton soup which mom made.'

b. $\{$ Emmáka mantin mantukuk $m E k E s$ 'E\} '(I) ate a wonton soup which MOM made'

c. \{Emunáka\} \{mantín mantukuk mEkEs'E\} '(I) ate a wonton soup which mom MADE'

d. $\{E m m a ́ k a\}$ \{mantîn $\}$ (mantúkuk mEkEs'E\} '(I) ate A WONTON SOUP which mom made'

Both examples are cases where the whole utterance consists of one Intonational Phrase. (10) is an example of a syntactic structure $\mathrm{NP}_{\text {AdjP }}[[\mathrm{Adv}][\text { Adj }]]_{\text {AdjP }}[$ Noun $\left.]\right]_{\mathrm{NP}}$ and $(11)$ has the syntactic structure ${ }_{s}\left[{ }_{N P}\left[S[[N P][V P]]_{S}[\text { head Noun }]\right]_{N P}[V P]\right]_{S}$. The P-Phrases in (10a) and (11a) above are for the neutral utterance, 'neutral' in the sense that it is uttered without focusing any special P-Word. (10b) and (11b) examples are in the case of when the first P.Word is emphasized, with the whole utterance forming one P-Phrase. ' $c$ ' examples are of when the second P-Word is emphasized, resulting in two P-Phrases.

Sentences (10d) and (11d), where the final P-Phrase is emphasized, show the same structure of P-Phrases as (10a) and (11a). However, the final P-Phrase of the ' $d$ ' utterances is phonetically different from those of the ' $a$ ' utterances; the F0 peak of :the final P-Phrase is higher in the ' $d$ ' version than it is in the case of the 'neutral' utterance, the duration of the word is longer than normal, and the intensity of the word is stronger than normal. The comparison of emphasized with unemphasized accentual patterns in (11) is displayed in Figure 4.

As shown above, if any word in a sentence is focused it initiates a new P-Phrase, which absorbs all following P-Words regardless of syntactic boundaries. In the case of (11c), a verb in a Relative clause, a head noun, and a main verb all form one P-Phrase. In other words, the principle 'one P-Word equals one P-Phrase' is overridden by semantic or pragmatic factors and, therefore, the arrangement of P-Phrases is not always isomorphic to syntactic structure. In summary, a Chonnam P-Phrase usually consists of one P-Word, thus, the domain of P-Phrase often matches to a syntactic constituent. However, this P-Phrase formation rule is overridden by semantic factors, or by focus, or by the length of a constituent.

' Usually, if a verb is closely related to a single object noun semantically and contextually, the verb P-Word does not form its own P-Phrase. So, for example, if a verb is pEryEtt'a 'threw' in this example, it is only when the noun is in narrow-focus that the Noun + Verb forms one P-Phrase. On the other hand, if 'ate' is emphasized the sentence would form four P-Phrases as in \{Emmáka\} (mantîn\} \{mantukuk\} \{mEkÉs'E\}. 


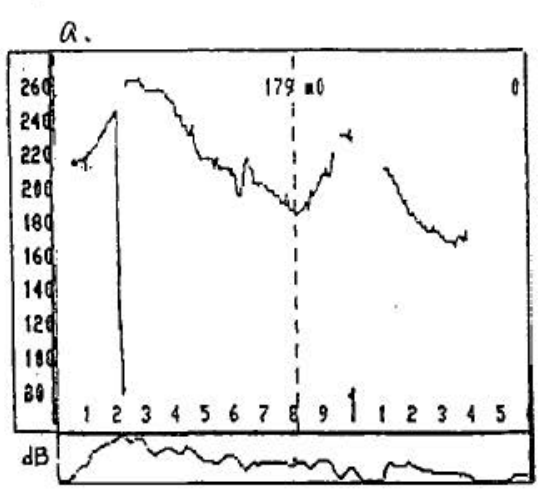

No special emphasis

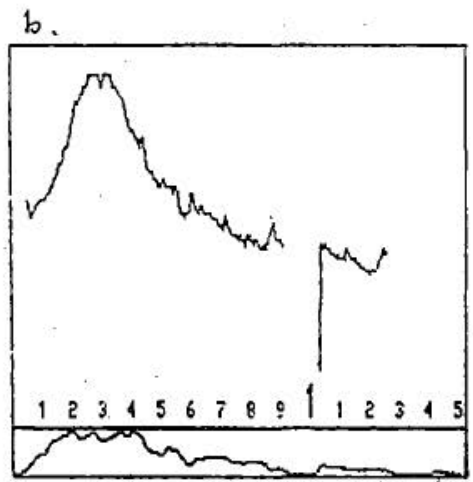

'Emmaka' is emphasized c.

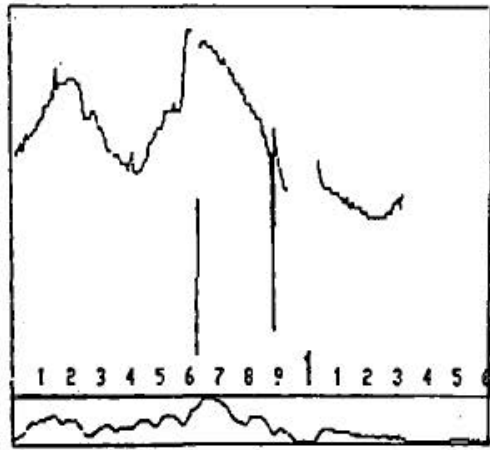

'mantin' is emphasized d.

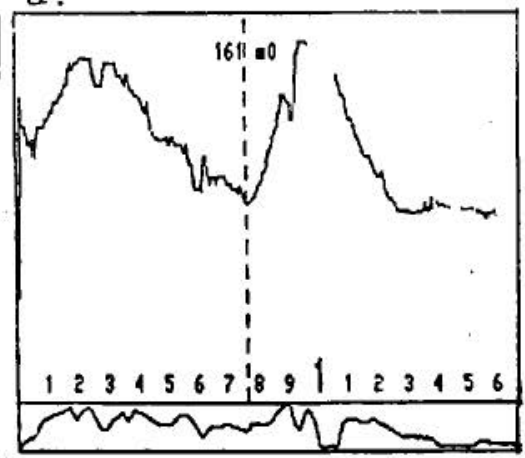

'mantukuk' is emphasized

Figure 4: Fo tracks of utterances in (11) above. 


\subsection{Prosodic Structures of Chonnam}

So far it has been shown that the domain of the Chonnam accentual pattern is the P-Phrase and that it is not isomorphic to syntactic structure. Furthermore, if we compare F0 contours of each P-Phrase in an utterance, we also see that the P-Phrases have phonetically different FO values for the same High tone or Low tone. For example, in an (Adv\} \{Adj\} [Noun] structure, while the Adv's and the Adj's F0 values are similar to each other, the peak F0 value of the third P-Phrase, the Noun, is lower than that of the preceding P-Phrases. And in an utterance consisting of \{Subj. of Rel. Cl.\} \{Verb of Rel. Cl.\} \{head Noun\} [main VP\}, the F0 peak of the verb in the relative clause is phonetically lower than that of the preceding Subject's P-Phrase, indicating that the second P-Phrase is downstepped, but the head noun's F0 peak is as high as the F0 peak of the preceding subject's P-Phrase, or at least it is not lower than the P-Phrase of the preceding relative verb.

So we can assume that between the P-Phrase of Relative verb and that of head noun there is some kind of phrase boundary which blocks the application of downstep. This means that there is a higher prosodic unit within which downstep can occur. Figure 5 shows the phenomenon of downstep within some prosodic unit higher than P-Phrases. The top utterances are aca 'very' + noóran 'yellow' + súúkEn 'a towel'; aca + noóran + moóca 'a hat'. The bottom utterance is apÉcik'esE 'Father-Subject marker' + Emmáhanthe 'Mother-Dative marker' + cusîn 'to give-honorific marker-Rel.marker' + otkamil 'a cloth-Object marker' + marás'ninte 'to give-PAST-but' $\Rightarrow$ '(I) rolled a cloth which Father gave to Mom, but...'.

The utterances in Figure 5 were said in a 'neutral' way. In the F0 track of Figure 5(c), the first three P-Phrases form one group separately from the fourth P-Phrase, in that the second and the third P-Phrase each is downstepped from its previous P-Phrase, but the 4th P-Phrase is not downstepped relative to the 3rd P-Phrase. And the 5th P-Phrase is again downstepped from the 4th P-Phrase, so that these two together form another prosodic domain. So we can assume there are two. prosodic domains for downstep in the utterance.

We can also see that there are two domains of downstep in the F0 track of Figures 5(a) and 5(b). In these utterances, the FO contour of the third P-Phrase is subordinate to that of the preceding P-Phrase, but the F0 contour of the second P-Phrase is not subordinate to that of the first P-Phrase. Thus, the second and the third P-Phrase form one prosodic unit in a level higher than the P-Phrase level. In other words, there are three P-Phrases and above them there are two prosodic units which are the domain of downstep. At the same time, this shows that the higher prosodic phrase is also not isomorphic to syntactic structure since the adverb which is the first P-Phrase and the adjective that it modifies (the 2nd phrase) belong to different downstep domains even though they form an Adjective Phrase syntactically. 
Jun: Accentual Pattern and Prosody of Chonnam
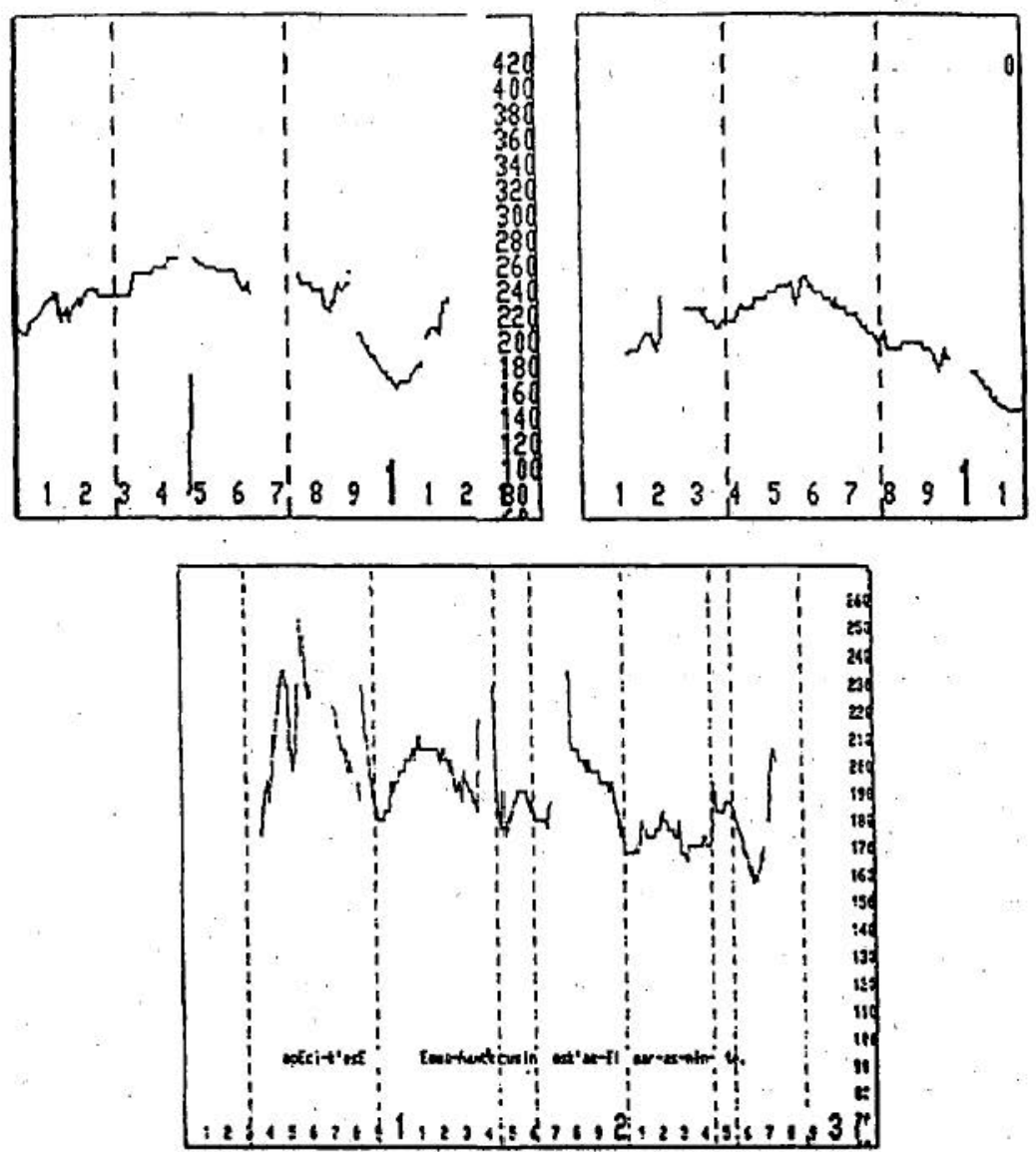

Figure 5: Downstep of P-Phrases.

Moreover, if we consider an utterance containing more than one Intonational Phrase we can also find that the Intonational Phrase is not the prosodic unit immediately higher than the P-Phrase, because we can find that within one Intonational Phrase, there is more than one phrasal domain where downstep occurs. The domain immediately higher than the P-Phrase has no special boundary tone while an Intonational Phrase necessarily has $\mathrm{H}$ or $\mathrm{HL}$ boundary tone. Figure 6 . 
shows F0 contours for three utterances, each of which is two intonational phrases, listed below:

a. Emma 'mother' + $k a$ 'Subj' + ponecu 'to send' $+n$ 'Rel marker' + nooran 'yellow' + mooca 'a hat' + nin 'TOPIC marker', acikto 'still' + an 'not' $+o$ 'to come' + ass 'PAST' $+E$ 'verbal ending'. $\Rightarrow$ $\{\{$ Emmáka\} (ponécun $\}\}\{\{$ noóran $\}$ (moócanin $\}\}\left\{\left\{a c i k t^{\prime} o\right\}\right.$ \{anwáts'E $\left.\}\right\}$.

b. $a c u$ 'very' + $k^{h_{i}+n}$ 'big' + c'aaNE 'an eel' + ka 'Subj.', siicaN 'a market' + $e$ 'Locative marker' + nao 'to appear' + ass 'PAST' + ninte 'but', $n E m i$ 'too much' + pis' $a$ 'to be expensive' + tira 'verbal ending'. $\Rightarrow$

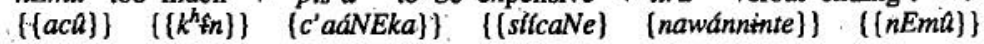
$\{($ pis'atira $\}\}$.

c. $y E N E$ 'English' + sEnseN ' 'a teacher' + $t l$ 'Subj' + mana 'to meet' + ass 'PAST' + ninti 'but', mom 'a body' + i 'Subj.' + maani 'much' + na 'to feel better' + inkEkat 'to be likely' + ira 'verbal ending'. $\Rightarrow$ $\{\{y E N E ́ s E n s e N i t\}$ \{manánninti $\}\}\{\{$ momî $\}\}\{($ maáni $\}$ (nałnkekatt'Era $\}\}$.

All these utterances were read in a normal speed and without focusing any specific word: In the first two utterances we find two and three domains of downstep within the first Intonational Phrase, respectively. The Intonational Phrasing is clear from the $\mathrm{H}$ boundary tone in the middle of the utterance (right before the double dashed line). In the 3rd utterance, the second Intonational Phrase has two domains of downstep, whose boundary is marked by a single dashed line. So, following Beckman and Pierrehumbert (1986), I assume the domain of downstep is an Intermediate: Phrase immediately higher than the P-Phrase but immediately lower than Intonational Phrase. An Intermediate Phrase can consist of one P-Phrase in a 'neutral' utterance,' as in the first Intermediate Phrase of each Intonational Phrase of the 2nd utterance in Figure 6. But when one P-Phrase is focused or emphasized, it always takes up the whole Intermediate Phrase, suppressing all following P-Phrases boundaries, if there are any. Given these prosodic units, we can give phonological descriptions for phonetically different data. Now if we look at Figure 4 again, we can find that the second P-phrase in ' $d$ ' is not downstepped from the first P-phrase while that of ' $a$ ' is downstepped. Thus we can tell that an emphasized P-phrase initiates a new Intermediate phrase. Therefore, the prosodic "structure - of ' $\mathrm{a}$ ' would be' one Intonational structure with one Intermediate structure, while that of ' $\mathrm{d}$ ' would be one Intonational structure with two Intermediate structures. 

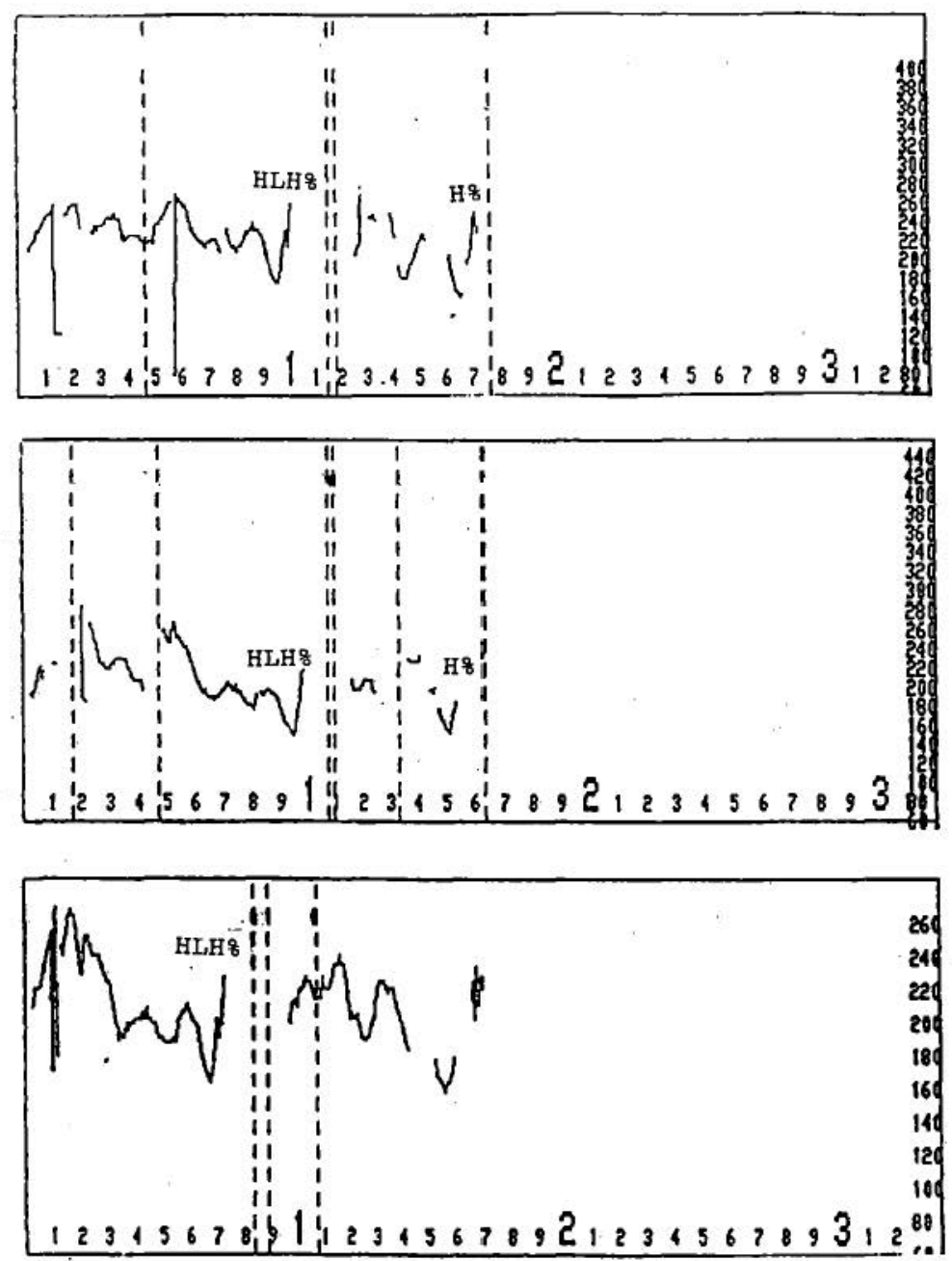

Figure 6: Utterances of two Intonational Phrases in (12). Single dashed line marks a boundary between Intermediate phrases and a double dashed line marks a boundary between Intonational Phrases. 
Accordingly, the prosodic or phonological structure of Chonnam can be represented in the following fashion:

(13)

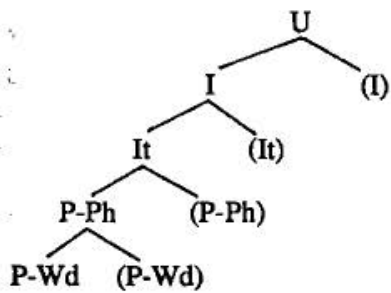

Here ' $U$ ' stands for Utterance, ' $I$ ' for Intonational Phrase, 'It' for Intermediate Phrase, 'P-Ph' for P-Phrase, and 'P-Wd' for P-Word.

This prosodic structure of Chonnam has all the properties of prosodic structure claimed by Nespor and Vogel (1986) in that, first, it consists of prosodic units of different types and, second, for any prosodic unit, an utterance is exhaustively parsed into a sequence of such units, and third, the prosodic units are ordered in a hierarchy.

In summary, the Chonnam prosodic structure consists of four levels of prosodic units above the P-Word level, which is the domain of most segmental phonological rules. These levels are the Utterance, the Intonational Phrase, the Intermediate Phrase, and the P-Phrase. These levels are defined as follows: the P-Phrase is the domain of the Chonnam accentual pattern; it can consist of one or more P-Words and is not always isomorphic to syntactic structures due to semantic factors, focus variations or length of the syntactic constituent. The Intermediate Phrase is the domain of downstep of P-Phrases; it can consist of more than one P-Phrase but usually contains fewer than four. The Intonational Phrase can contain more than one Intermediate Phrase and is marked by an intonational boundary tone, $\mathrm{H}$ or $\mathrm{HL}$, which is not found at any other phrase boundary. Finally, the Utterance can contain more than one Intonational Phrase.

\section{Acknowledgements}

I would like to thank Mary Beckman who, as my advisor, has helped me finish this paper with valuable comments and ideas. I also would like to thank David Odden who for the first time made me realize the tonal properties of the Chonnam dialect and has given valuable comments and criticism. Finally, I would like to thank the Korean seminar group for giving me the opportunity to present and develop this paper. 


\section{References}

Beckman, M. and J. Pierrehumbert. 1986. Intonational Structure in Japanese and English. Phonology Yearbook 3: 255-309.

Cho, Young-mee Y. 1987. The Domain of Korean Sandhi Rules. Paper presented at the LSA meeting.

1988. Syntax and Phrasing in Korean. To appear in Phonology Syntax Connection.

Clements, G. N. 1985. The Geometry of Phonological Features. Phonology Yearbook 2: 225-252.

Han, M. S. and R. S. Weitzman. 1970. Acoustic Features of Korean /P, T, K/, /p, $\mathrm{t}, \mathrm{k} /$ and $/ \mathrm{p}^{\mathrm{h}}, \mathrm{t}^{\mathrm{h}}, \mathrm{k}^{\mathrm{h}} \%$. Phonetica 22: 112-128.

Hardcastle, W. J. 1973. Some Observations on the Tense-Lax Distinction in Initial Stops in Korean. Journal of Phonetics 1: 263-272.

Hombert, J. M. 1978. Consonant Types, Vowel Quality, and Tone. Victoria Fromkin ed. Tone: A Linguistic Survey. Academic Press.

Iverson, G. K. 1983. Korean s. Dept. of Linguistics, Univ. of Iowa.

Kaisse, E. M. and P. A. Shaw. 1985. On the Theory of Lexical Phonology. Phonology Yearbook 2: 1-30.

Kagaya, R. 1971. Laryngeal Gestures in Korean Stop Consonants. Annual Bulletin, Research Institute of Logopedics and Phoniatrics, University of Tokyo 5: 15-24.

1974. A Fiberscopic and Acoustic Study of the Korean Stops, Affricates and Fricatives. Journal of Phonetics 2: 161-128.

Kim, C. W. 1965 . On the Autonomy of the Tensity Feature in Stop Classification (with special reference to Korean stops). Word 21: 339-359. 1970. A Theory of Aspiration. Phonetica 21: 107-116.

McCawley, J. D. 1978. What is a Tone Language? Victoria Fromkin ed. Tone: A Linguistic Survey. Academic Press.

Mohanan, K. P. 1986. The Theory of Lexical Phonology. D. Reidel Publishing Co. Dordrecht, Holland.

Nespor, M. and Irene Vogel. 1986. Prosody Phonology. Foris, Dordrecht. 
Odden, D. 1987. Kimatuumbi Phrasal Phonology. Phonology Yearbook 3:13-36.

Pulleyblank, D. 1986. Tone in Lexical Phonology. D. Reidel Publishing Company.

Ramsey, S. 1978. Accent and Morphology in Korean Dialect: A Descriptive and Historical Study. Top Publishing Co. Korea.

Selkirk, E. 1980. Prosodic Domain in Phonology: Sanskrit Revisited. M. Aronoff and M. L. Kean eds. Juncture. Saratoga: Anma Libri.

\section{Yearbook 3.}

1986. On Derived Domains in Sentence Phonology. Phonology

Yi, S.O. 1983. Remarks on Tone in Middle Korean. The Korean National Commission for UNESCO ed. The Korean Language, Pace International Research, Inc., Oregon, U.S.A. 